\title{
Influence of Acellular Natural Lung Matrix on Murine Embryonic Stem Cell Differentiation and Tissue Formation
}

\author{
Joaquin Cortiella, M.D., M.P.H., Jean Niles, M.A., ${ }^{2}$ Andrea Cantu, B.A., ${ }^{3}$ Andrea Brettler, \\ Anthony Pham, M.D., ${ }^{4}$ Gracie Vargas, Ph.D., ${ }^{5}$ Sean Winston, B.A., ${ }^{2}$ Jennifer Wang, ${ }^{6}$ \\ Shannon Walls, M.S., ${ }^{2}$ and Joan E. Nichols, Ph.D. ${ }^{2}$
}

We report here the first attempt to produce and use whole acellular (AC) lung as a matrix to support development of engineered lung tissue from murine embryonic stem cells (mESCs). We compared the influence of AC lung, Gelfoam, Matrigel, and a collagen I hydrogel matrix on the mESC attachment, differentiation, and subsequent formation of complex tissue. We found that AC lung allowed for better retention of cells with more differentiation of mESCs into epithelial and endothelial lineages. In constructs produced on whole AC lung, we saw indications of organization of differentiating ESC into three-dimensional structures reminiscent of complex tissues. We also saw expression of thyroid transcription factor-1, an immature lung epithelial cell marker; prosurfactant protein C, a type II pneumocyte marker; PECAM-1/CD31, an endothelial cell marker; cytokeratin 18; $\alpha$-actin, a smooth muscle marker; CD140a or platelet-derived growth factor receptor- $\alpha$; and Clara cell protein 10. There was also evidence of site-specific differentiation in the trachea with the formation of sheets of cytokeratinpositive cells and Clara cell protein 10-expressing Clara cells. Our findings support the utility of AC lung as a matrix for engineering lung tissue and highlight the critical role played by matrix or scaffold-associated cues in guiding ESC differentiation toward lung-specific lineages.

\section{Introduction}

$\mathbf{T}$ HE HETEROGENEOUS CELL POPULATION of the lung is supported by a unique organ-specific extracellular matrix (ECM) network made up primarily of collagen and elastin as well as other matrix components critical to lung function. ${ }^{1,2}$ It is because of the complex nature of lung ECM that development of matrix materials suitable for engineering lung tissue has not been realized, but this must occur before we can begin to produce tissues worthy of research or clinical application. At present the development of lung tissue equivalents has not been significant, and only a few reports provide evidence of development of in vitro or in vivo engineered lung. ${ }^{3-8}$ All of these studies utilized simple matrices that were not designed to meet the requirements for lung in terms of matrix composition, elasticity, or porosity. ${ }^{9,10}$

Decellularized tissues and organs have been used successfully as scaffolds for engineering a variety of tissues. ${ }^{11-16}$ Most decellularization methods allow for retention of some of the natural mechanical and biologic properties inherent in the natural tissue. An attempt at repopulating a decellular- ized heart with cardiac and endothelial cells demonstrated that the acellular (AC) heart allowed for cardiac muscle attachment and supported muscle contraction or pump function by the recellularized organ. ${ }^{15}$ This was followed more recently by use of an AC cadaveric trachea, which, when repopulated with the patient's own mesenchymal stem and mature epithelial cells, was effectively transplanted into a patient with bronchial stenosis. ${ }^{16}$ The success of these studies led us to hypothesize that the best matrix to support lung tissue engineering might be the natural cytoskeleton, or ECM, of the lung. Natural lung contains all of the ECM components necessary to provide structural support for the biochemical and biophysical interactions that occur in the lung, and natural ECM has been shown to support attachment of adult type II pneumocytes. ${ }^{17}$ Ultimately, rather than attempting to design matrices that mimic lung ECM it may be better to utilize natural lung ECM that already meets the biocompatibility and elasticity requirements necessary to support the rhythmic expansion and contraction experienced by the lung during the process of breathing and oxygenation.

The aim of this study was to produce AC trachea with attached lungs and to investigate the response of murine

\footnotetext{
Departments of ${ }^{1}$ Anesthesiology and ${ }^{2}$ Internal Medicine, Infectious Diseases, University of Texas Medical Branch, Galveston, Texas.

${ }^{3}$ Stanford University, Palo Alto, California.

${ }^{4}$ Department of Internal Medicine, Brown Medical School, Providence, Rhode Island.

${ }^{5}$ Center for Biomedical Engineering, University of Texas Medical Branch, Galveston, Texas.

${ }^{6}$ Department of Bioengineering, Duke University, Durham, North Carolina.
} 
embryonic stem cells (mESCs) to AC rat lung in terms of cell attachment, survival, and differentiation along lung-specific lineages. We used culture of mESC on whole AC rat lung to provide insight into the role played by matrix composition on ESC lung lineage commitment and the capability of matrix to promote site-specific differentiation of mESCs and formation of lung tissue.

\section{Materials and Methods}

\section{Tissue decellularization procedure}

To develop our decellularization procedure, 96 sets of rat trachea with attached lungs were excised and cell membranes and nuclear material were removed using a process that combined freezing, enzymatic digestion, and detergent treatment (Fig. 1). Whole trachea, esophagus, and lungs were excised, and tissues were cleaned to remove attached esophageal, lymphatic, and connective tissues before lungs were weighed and photographed (Fig. 2A). Lungs were stored at $-70^{\circ} \mathrm{C}$ until decellularization was initiated. Lungs were later thawed in a $40^{\circ} \mathrm{C}$ water bath and were flash frozen on dry ice followed by quick thawing; this process was repeated four times to enhance cell damage and facilitate cell loss. Three microliters of $2 \%$ sodium dodecyl sulfate (SDS; Sigma) was then injected into the trachea and into the right and left bronchus before placing the lungs into a $50 \mathrm{~mL}$ chamber of a rotating bioreactor (Synthecon) containing 1\% SDS for 1, 2, 3, 4, or 5 weeks at room temperature. Tissues were maintained at a rotational speed of $2.5 \mathrm{rpm}$, which provided constant mechanical agitation of the tissue, and chambers were allowed continuous circulation of fresh $1 \%$ SDS and removal of cell debris. Confocal microscopy was used to evaluate loss of cell-membrane-associated major histocompatability complex-1 (MHC-1) and nucleic acids. Verification of cell removal was done by staining for residual membrane expressing MHC-1 as well as for the presence of DNA using 4',6-diamidino-2-phenylindole (DAPI; Molecular Probes) or propidium iodide (PI) staining (Sigma). In the examination of loss of MHC-1 and DAPI staining, each slide was stained with DAPI and human- or rat-specific MHC-1 and slides were then scored by counting positively DAPIstained nuclei or MHC-1-positive areas in five high-powered fields under $\times 400$ magnification. Results were confirmed through a second reading by another person. At least three replicate measurements of each slide were performed by the same observer and 10 randomly selected slides were chosen from each set of serial sections through the entire piece of lung. Images were selected for inclusion in the article based on scoring of the slides.

After 5 weeks of SDS treatment, tissues were washed and placed in a mixture of $0.02 \mathrm{mg} / \mathrm{mL}$ DNAase and $20 \mu \mathrm{g} / \mathrm{mL}$ RNAase (Sigma) in the bioreactor chamber for $24 \mathrm{~h}$ at $37^{\circ} \mathrm{C}$. Then whole trachea and lungs were washed for $24 \mathrm{~h}$ in Dulbecco's phosphate-buffered saline with antibiotics (streptomycin $[90 \mu \mathrm{g} / \mathrm{mL}]$, penicillin $[50 \mathrm{U} / \mathrm{mL}]$, and the antimycotic amphotericin B [ $25 \mu \mathrm{g} / \mathrm{mL}]$; Gibco Industries) in a $50 \mathrm{~mL}$ rotary bioreactor chamber at room temperature. Finally, AC lungs were refrigerated at $4^{\circ} \mathrm{C}$ for 1 week or frozen at $-70^{\circ} \mathrm{C}$ until used. Before recellularization with $\mathrm{mESC}, \mathrm{AC}$ lungs were washed with Dulbecco's modified Eagle's medium (DMEM)-F12 for $24 \mathrm{~h}$ in a rotary bioreactor. For matrix comparison studies portions of distal lung were cut into

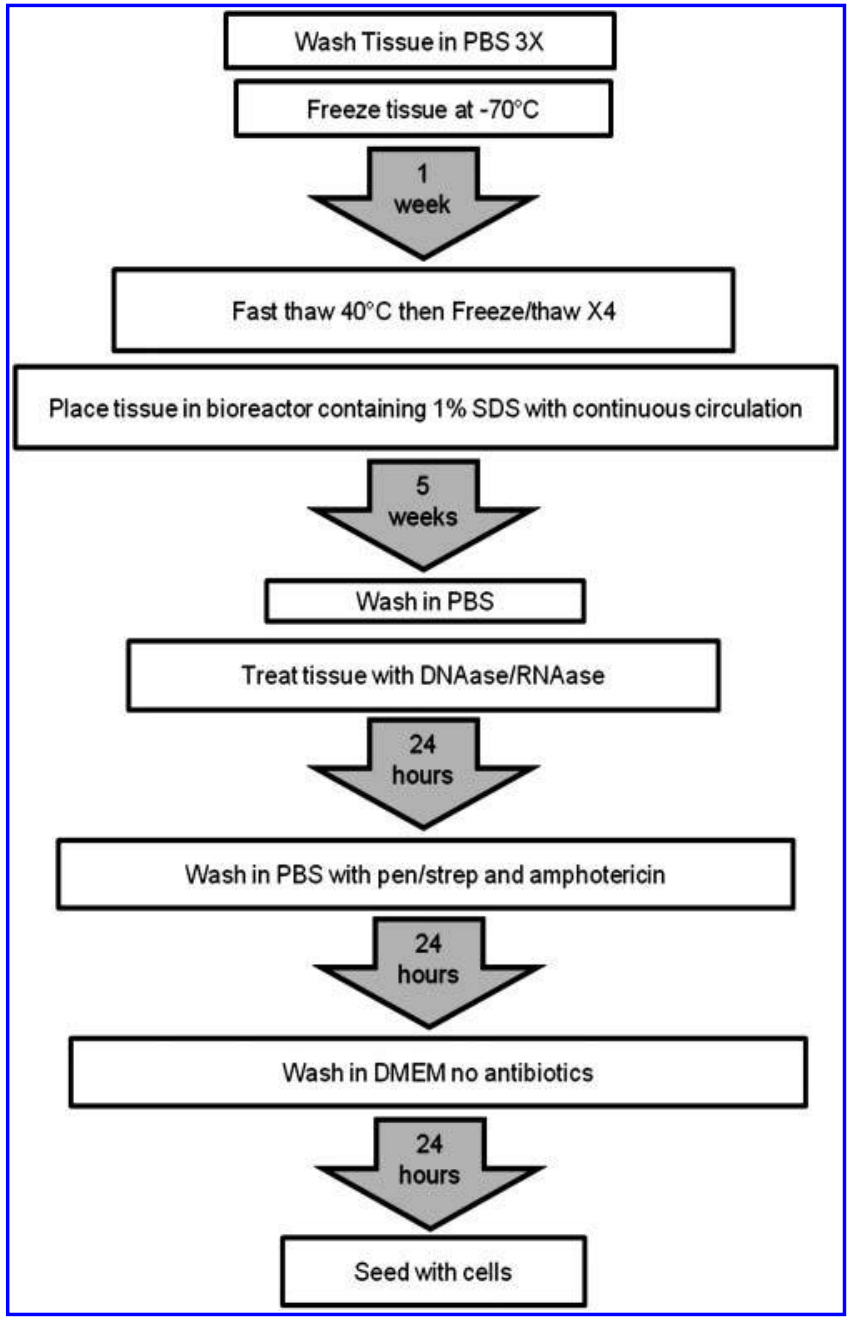

FIG. 1. Lung decellularization protocol. Flow chart showing physical (freezing), mechanical (rotation of bioreactor with circulation of detergent), and enzymatic (DNAase and RNAase treatment) steps necessary to reduce levels of Rat MHC-1 and DNA/RNA in AC lung tissue. MHC-1, major histocompatability complex-1; AC, acellular.

$0.5 \mathrm{~cm}$ pieces before recellularization as described below. For these experiments rat lung was used instead of mouse lung due to the larger size of the rat tissues, which made the processes of excision, decellularization, and recellularization easier to accomplish. Use of rat lungs also allowed us to produce large pieces of distal lung for studies to compare AC lung with other matrix materials.

\section{Murine embryonic stem cells}

C57BL6 (F) + 129/vs. mESC were purchased from Open Biosystems. Postcryogenic viability was determined to be approximately $80 \%$. The embryonic feeder cells that were used were mitotically inactivated by treatment with mitomycin C by Open Biosystems before shipment. mESCs (Open Biosystems) were cultured on appropriate feeder cells as previously described by the manufacturer. mESCs were maintained in a six-well tissue-culture-treated plate on which mouse fibroblast feeder cells had been established. Wells were seeded at between $1.5 \times 10^{5}$ and $4 \times 10^{5}$ cells/well and 
split when confluency reached about $80 \%-85 \%$. The medium was replenished or replaced daily. Cells were placed in DMEM with $15 \%$ fetal calf serum, and supplemented with Lglutamine, sodium pyruvate, nonessential amino acids, penicillin-streptomycin, b-mercaptoethanol, and Leukemia Inhibitor Factor according to the manufacturer's recommendations. Cells were cultured at $37^{\circ} \mathrm{C}$ with $5 \% \mathrm{CO}_{2}$. Differentiation of embryoid bodies (EBs) was accomplished by limited trypsin digestion of mESC colonies $24 \mathrm{~h}$ postpassage and suspension of the cells in nontissue culture treated Petri dishes (Corning-Costar). EBs were cultured in suspension for 10 days and then placed into gelatinized six-well plates. EBs were grown for 15-25 days as necessary. Percent viability of mESCs collected from the EBs at time of use was $\geq 95 \%$ for all cultures. All embryonic and feeder cell lines were tested and shown to be mycoplasma negative before use.

\section{Seeding and culture of matrices}

To evaluate the ability of AC rat lung to support attachment and survival of cells, we compared growth of mESCs on AC lung to growth on Matrigel and Gelfoam and a type I collagen pluronic F-127 (PF-127) hydrogel matrix (collagen I/PF-127) produced in our laboratory. Gelling of microfluidically patterned collagen I has shown previously to produce threedimensional (3D) matrices that mimic natural lung ECM. ${ }^{18}$ On the basis of these studies we produced a collagen I/PF-127 hydrogel matrix formed by mixing equal volumes of $8 \mathrm{mg} / \mathrm{mL}$ collagen I (Sigma) with 40\% PF-127 and then pipetting the mixture into $0.5 \mathrm{~cm}^{3}$ plastic molds. The final matrices of $4 \mathrm{mg} /$ $\mathrm{mL}$ collagen I (Sigma) with 20\% PF-127 were allowed to solidify at room temperature before use.

Distal AC lung, Matrigel, and Gelfoam were cut into six equal-sized $0.5 \mathrm{~cm}^{3}$ pieces. About $2 \times 10^{6} \mathrm{mESC}$ suspended in $0.1 \mathrm{~mL}$ of PF-127 hydrogel were injected through a 20-gauge catheter into the center of each of the six $0.5 \mathrm{~cm}^{3}$ pieces of AC lung, Matrigel, or Gelfoam, or into six $0.5 \mathrm{~cm}^{3}$ pieces of collagen I/PF-127 matrix. The seeding process was followed by a $5 \mathrm{~min}$ centrifugation at 800 revolutions per minute (RPM) (72 relative centrifugal force [RCF]) to help spread cells throughout the matrix. The mESC/AC matrix constructs were then placed into a 24-well culture dish that contained the cell culture medium (see below) to allow for binding of mESC to the matrix materials before bioreactor culture. Constructs were cultured at $37^{\circ} \mathrm{C}$ in a $5 \% \mathrm{CO}_{2}$ incubator for $24 \mathrm{~h}$ before placing each group of six cell/matrix constructs in a separate rotary bioreactor chamber containing the lung differentiation medium for 6 days. For 2D plate culture of mESCs $2 \times 10^{6}$ cells per well were cultured in cell the culture medium (above) or in the lung differentiation medium in 24-well plates.

\section{Seeding and growth of cells on whole AC lung}

For recellularization of whole trachea with attached lungs, $1 \times 10^{6} \mathrm{mESC}$ suspended in $0.5 \mathrm{~mL}$ of PF-127 (15\% in DMEM) were injected into the right and left main bronchus of the AC lung using a 20-gauge catheter for a total of $2 \times 10^{6}$ cells/ lung. The seeding process was followed by a $5 \mathrm{~min}$ centrifugation at $800 \mathrm{rpm}(72 \mathrm{RCF})$ to help spread cells throughout the lung. The lungs were then placed into a $50 \mathrm{~mL}$ rotating bioreactor (Synthecon) chamber that contained the lung differentiation medium and were cultured at $37^{\circ} \mathrm{C}$ in a $\mathrm{CO}_{2}$ incubator for 14 or 21 days. The medium was circulated by a continuous pump action of the bioreactor at a speed of $2.0 \mathrm{rpm}$. Five lungs were harvested after 14 days of culture and the remaining five lungs were harvested after 21 days. Lungs were fixed in $4 \%$ paraformaldehyde (PAF) and evaluated as described below.

\section{Lung cell culture medium and lung differentiation medium}

The lung cell culture medium was made as previously described $^{3}$ using DMEM/F-12 (Mediatech, Inc.) with addition of $33 \mathrm{mM}$ glucose (Sigma), insulin $(20 \mu \mathrm{g} / \mathrm{mL}$; Sigma), transferrin $(10 \mu \mathrm{g} / \mathrm{mL}$; Sigma), selenium (100 nM; Sigma), putrescine (10 mM; Sigma), epidermal growth factor (20 ng/ $\mathrm{mL}$; PeproTech, Rocky Hill, NJ), and fibroblast growth factor ( $20 \mathrm{ng} / \mathrm{mL}$; Collaborative Biomedical). The lung differentiation medium was made using DMEM/F-12 (Mediatech, Inc.) with addition of $33 \mathrm{mM}$ glucose (Sigma), insulin $(20 \mathrm{mg} / \mathrm{mL}$; Sigma), transferrin (10 mg/mL; Sigma), selenium (100 nM; Sigma), putrescine (10 $\mathrm{mM}$; Sigma), epidermal growth factor ( $25 \mathrm{ng} / \mathrm{mL}$; PeproTech), insulin-like growth factor-1 ( $5 \mathrm{ng} /$ $\mathrm{mL}$; PeproTech), Activin A (30 ng $/ \mathrm{mL}$; SBH Biosciences or R\&D Biosystems), and lung homogenate $(40 \mu \mathrm{L} / \mathrm{mL})$. Lung homogenate was made by homogenizing 10 sets of C57B6 mouse lungs in $5 \mathrm{~mL}$ of the lung differentiation medium. Homogenate was centrifuged to remove large pieces of cell debris, and the resulting supernatant was filtered through a $4 \mu \mathrm{m}$ and then through a $1 \mu \mathrm{m}$ filter. Lung homogenate was stored at $-70^{\circ} \mathrm{C}$ until used. The lung differentiation medium containing Activin A and lung homogenate was constantly circulated through the bioreactor chamber. Two days after initiation of bioreactor culture, use of Activin A was discontinued and fibroblast growth factor 2, 7, and 10 [25 ng/ $\mathrm{mL}$ each] (Collaborative Biomedical) were added to the circulating medium for the remainder of the culture period (14 or 21 days).

\section{Quantitation of DNA in $A C$ rat lung}

DAPI or PI staining was used to document the loss of nuclei or DNA in lung tissue during the process of decellularization. For staining with DAPI, a DAPI stock solution $(5 \mathrm{mg} / \mathrm{mL} ; 14.3 \mathrm{mM}$ for the dihydrochloride or $10.9 \mathrm{mM}$ for the dilactate) was made by dissolving the contents of one vial (10 $\mathrm{mg}$ of DAPI) in $2 \mathrm{~mL}$ of deionized water, which was followed by sonication for $2 \mathrm{~h}$. For long-term storage the aliquots were stored at $-20^{\circ} \mathrm{C}$. For PI staining PI stock was made by dissolving PI $(1 \mathrm{mg})$ in $1 \mathrm{~mL}$ deionized water, which was stored at $4^{\circ} \mathrm{C}$. Working PI stain was made by adding PI ( $200 \mu \mathrm{L}$ of $1 \mathrm{mg} / \mathrm{mL}$; Sigma, BioSure, Molecular Probes) to $10 \mathrm{~mL}$ of Triton X-100 (0.1\% [v/v]; Sigma) in phosphatebuffered saline (PBS). Sections were incubated with dilute stain for $5 \mathrm{~min}$, rinsed several times in PBS, and then drained and mounted in Molecular Probes' SlowFade ${ }^{\circledR}$ Antifade Kit, SlowFade Light Antifade Kit, or ProLong ${ }^{\circledR}$ Antifade Kit.

To determine if DNA remained in the fully acellularized rat lung, strips of matrix were treated as previously described. ${ }^{19}$ Strips of AC lung were digested with proteinase K and extracted with phenol-chloroform-isoamyl alcohol (25:24:1), and aqueous layers were removed and ethanol was precipitated at $-20^{\circ} \mathrm{C}$ for $12 \mathrm{~h}$ to isolate any DNA present. The remainder of the protocol was followed as described and 


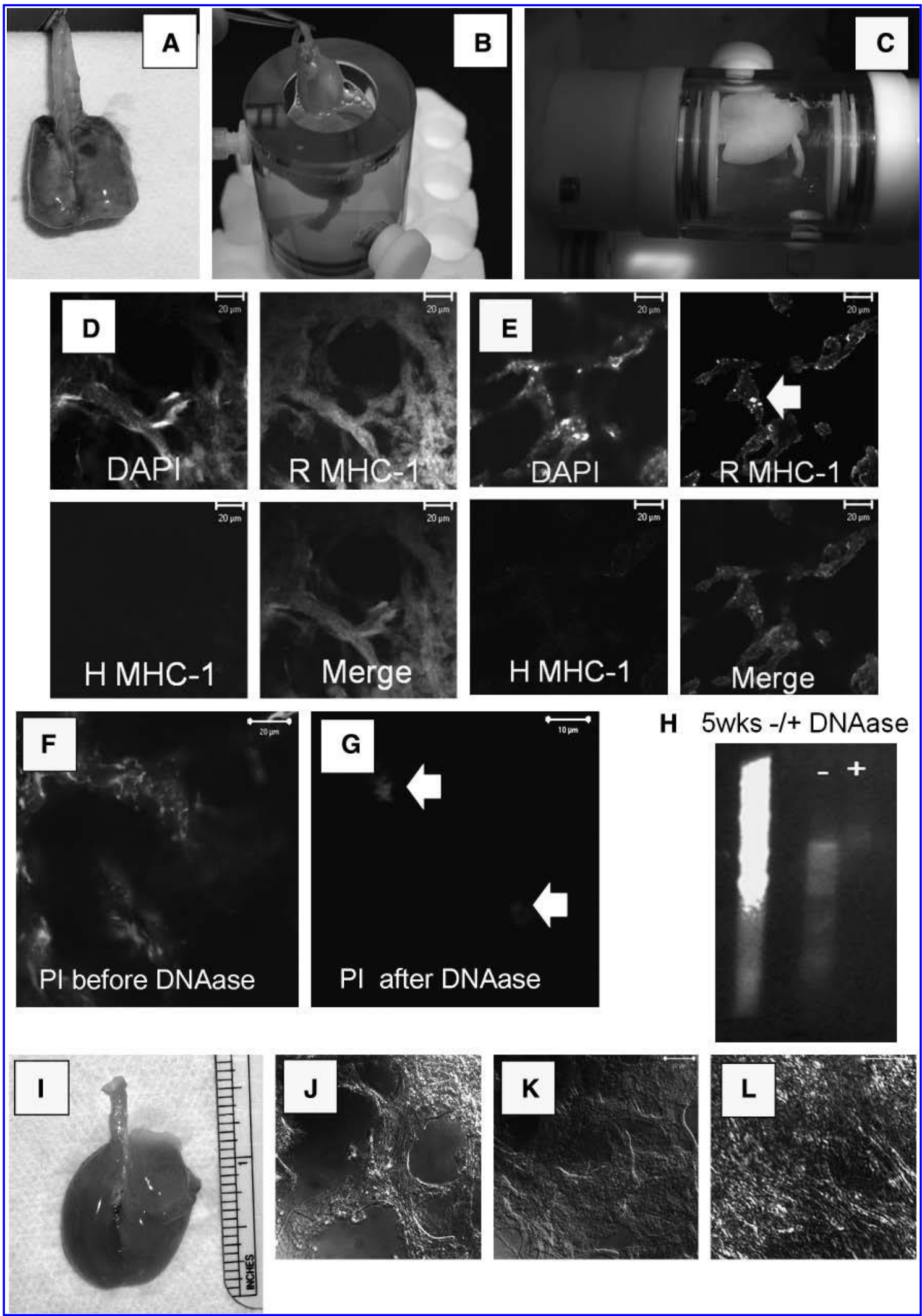


samples were separated by electrophoresis on a 3\% LMP agarose gel with ethidium bromide at $60 \mathrm{~V}$ for $1 \mathrm{~h}$, and observed with ultraviolet transillumination.

\section{Evaluation of $\mathrm{mESC} /$ matrix constructs}

Three-dimensional mESC/AC construct culture in a bioreactor was compared to $2 \mathrm{D}$ plate culture of mESC with and without the addition of the lung differentiation medium. Six $0.5 \mathrm{~cm}^{3}$ pieces of AC lung, Matrigel, Gelfoam, or collagen I/ PF-127 mESC/constructs were cultured in separate bioreactor chambers and were harvested after 7 days of culture. One quarter of each matrix was removed and sectioned to allow for microscopic examination of cell attachment to each matrix. Each portion of matrix was frozen in the tissue freezing medium (Triangle Biomedical Sciences) and serially sectioned on a Microm cryomicrotome (Thermo Scientific). To determine the distribution of cells, each slide was stained with DAPI and was then scored by counting positively DAPI-stained nuclei in five high-powered fields under $\times 400$ magnification. All slides were counted without knowledge of the matrix being examined, and results were confirmed through a second reading by another person. At least three replicate measurements of $\mathrm{DAPI}^{+}$cells were performed by the same observer in 10 randomly selected slides. The remaining cells from each individual $\mathrm{mESC} /$ matrix construct were collected after suspension of each matrix in $1 \mathrm{~mL}$ of $0.25 \%$ trypsin for $5 \mathrm{~min}$ followed by physical disruption by running each piece of construct against a fine mesh screen.

Cells from each piece of $\mathrm{mESC} /$ matrix construct were evaluated for cell viability, induction of apoptosis, and lungspecific differentiation after immunohistochemical staining with analysis by flow cytometry. Viability was analyzed by vital fluorescent staining (calcein acetoxymethylester [calcein-AM] and ethidium homodimer-1; Molecular Probes). Apoptosis in samples was determined by quantitation of DNA strand breaks using the terminal deoxynucleotidyl transferase dUTP nick end labeling (TUNEL) is a method for detecting DNA fragmentation by labeling the terminal end of nucleic acids Assay (In Situ Cell Death Kit; Boehringer Mannheim) as described in the manufacturer's instructions. The results from the evaluation of the influence of matrix on cell survival, apoptosis, and differentiation were compared to averages of 2D culture of six wells containing $2 \times 10^{6} \mathrm{mESC}$ per well cultured in 24 -well tissue culture plates with the addition of the lung differentiation medium. Twodimensional and 3D cultured mESCs were also examined for lung epithelial or endothelial lineage selection by immunostaining for expression of cytokeratin 18, CD31, and pro-surfactant protein C (pro-SPC) with analysis using flow cytometry.

\section{Immunohistochemistry}

For immunostaining, cell matrix constructs or whole lungs were fixed in $2 \%$ PAF in PBS overnight at room temperature. Portions of matrix constructs or lungs were frozen in the tissue freezing medium (Triangle Biomedical Sciences) and sectioned on a Microm cryomicrotome (Thermo Scientific). Rat and murine MHC-1, human MHC-1, CD31, and CD140a were evaluated as described by the manufacturer (BD Biosystems) using antibodies directly conjugated to fluorescein isothiocyanate, allophycocyanin, or PerCP-cyanin-5. Primary antibodies and dilutions used were anticollagen I (goat, 1/ 250; Santa Cruz Biologicals), antielastin (1/150; Santa Cruz Biologicals), cytokeratin-18 (mouse, 1:400; Chemicon), anticollagen IV (goat, 1/200 or 1/250; Santa Cruz Biologicals), proSPC (rabbit, 1/200; Chemicon), Clara cell protein-10 (CC10; goat, 1/250; Santa Cruz Biologicals), antilaminin (goat, 1/200; Santa Cruz Biologicals), $\alpha$-actin (rat monoclonal, 1/200; Abcam), thyroid transcription factor-1 (TTF-1; rabbit, 1/200; Millipore), and pan-cytokeratin (mouse, 1:200; Chemicon).

Tissue sections were incubated with primary antibody for $1 \mathrm{~h}$ at $4^{\circ} \mathrm{C}$ in a humid chamber, washed, and then incubated with secondary antibody for $30 \mathrm{~min}$ according to manufacturer's instructions. Internal proteins were stained after fixation of cells in PAF and incubation in BD Perm2 permeabilization solution as described by the manufacturer (BD Biosystems). For negative controls, corresponding immunoglobulin and species (IgG)-matched isotype control antibodies were used, or the primary antibodies were omitted and sections were stained with secondary antibodies alone to set baseline values for analysis markers or as tissue staining controls. Donkey anti-rabbit IgG conjugated to Rhodamine

FIG. 2. Evaluation of decellularization process. (A) Appearance of rat trachea with attached lungs immediately after excision. (B) Condition of whole rat lungs after freeze-thawing followed by treatment in $1 \%$ SDS for 1 week in a $50 \mathrm{~mL}$ bioreactor chamber. (C) Gross condition of whole lung after 1\% SDS treatment for 5 weeks. Lung is shown in the rotary bioreactor chamber during the final antibiotic/antimycotic wash. (D-G) Confocal images of $7 \mu \mathrm{m}$ frozen sections of whole lung (D) stained for the presence of cell-membrane-associated rat MHC-1 after 1 week in 1\% SDS treatment show extensive regions positive for cell debris. DAPI staining for nuclei/nuclear material also showed the presence of many intact nuclei. Staining with human MHC-1 was used as a negative control. Magnification $400 \times$. (E) Examination of $7 \mu \mathrm{m}$ tissue sections after 4 weeks of $1 \%$ SDS treatment demonstrated that a few areas remained positive for rat MHC-1 or DAPI. Arrow points to low level staining in tissue section. Staining with human MHC-1 was used as a negative control. Magnification $400 \times$. PI staining of tissue sections (F) before and (G) after DNAase/RNAase treatment indicated that significant loss of nuclear material had occurred. Arrows point to PI-positive regions. Magnification $400 \times$. (H) Gel electrophoresis was used to evaluate the DNA content within AC rat lung after 5 weeks of $1 \%$ SDS treatment with (-) and without (+) DNAase treatment. Gels indicated that trace amounts of DNA remained even after DNAase treatment of the lung ECM matrix. (I) At the end of the decellularization process, AC lung was uniformly clear and glassy in appearance. (J-L) Four micron frozen sections of AC rat lung matrix were photographed using transmitted white light using a Zeiss LSM 510 Meta inverted microscope to show the fibrillar network of the remaining ECM after successful decellularization of the tissues. These sections showed the AC lung ECM substructure in the regions corresponding to $(\mathbf{J})$ distal lung and $(\mathbf{K}, \mathbf{L})$ upper airway. Regions near $(\mathbf{K})$ the main bronchus near the carina, scale bar $=20 \mu \mathrm{m}$ and $(\mathbf{L})$ the trachea show the dense fibrous nature of upper lung, scale bar $=$ $10 \mu \mathrm{m}$. Magnification 400×. SDS, sodium dodecyl sulfate; DAPI, 4',6-diamidino-2-phenylindole; ECM, extracellular matrix; PI, propidium iodide; MHC, major histocompatability molecule; H, human; R, rat. 


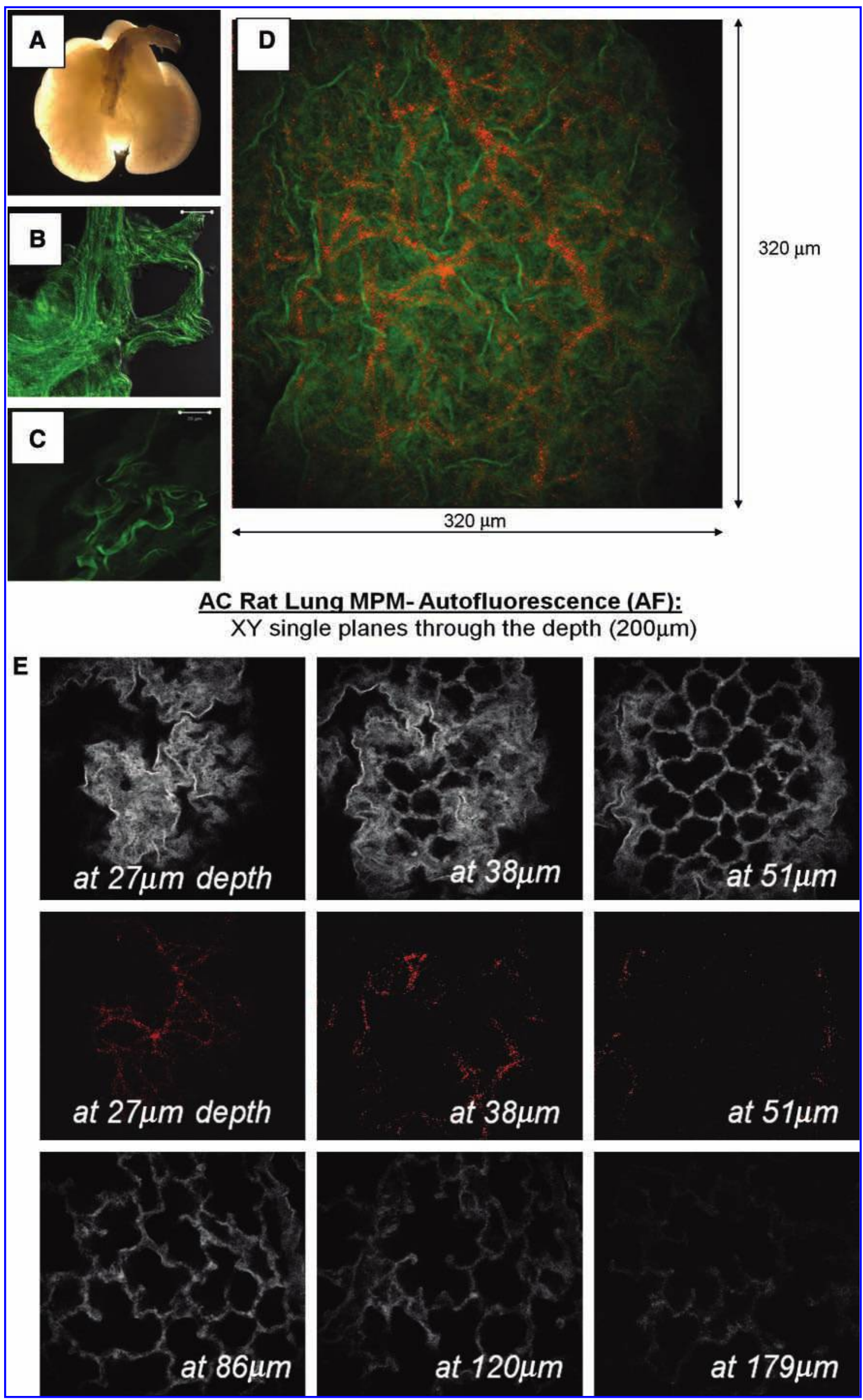


Red-X, donkey anti-goat IgG antibody conjugated to Alexa Fluor 680 (1:250; Invitrogen), rabbit anti-mouse IgG conjugated to Alexa Fluor 488 (1:400; Invitrogen), goat anti-rat IgG conjugated to Alexa Fluor 680 (1:250 dilution; Invitrogen), goat anti-rabbit highly cross absorbed IgG conjugated to Alexa Fluor 555 (1:250 dilution; Invitrogen), and donkey anti-goat IgG conjugated to Alexa Fluor 594 (1:250 dilution; Invitrogen) were used as secondary antibodies.

\section{Fluorescent microscopy, confocal microscopy, and flow cytometry analysis}

Fluorescent microscopy was done using a Zeiss Axioscope Fluorescent microscope or a Nikon T300 Inverted Fluorescent microscope (Nikon Corp.). Confocal microscopy was done on a Zeiss LSM 510 UV-META confocal microscope. For flow cytometry, cells were fixed with $2 \%$ PAF before analysis using a FACSAria instrument (BD Biosciences), with acquisition and analysis using the FACSDiva program (BD Biosciences). For each sample 10,000-20,000 cells were collected.

\section{Two-photon microscopy}

Two-photon microscopy was done with a Zeiss 410 Confocal Laser Scanning Microscope. Lung samples were imaged using multiphoton microscopy to detect tissue autofluorescence and second harmonic generation microscopy. Briefly, multiphoton excitation was from a titanium:sapphire laser (Tsunami, SpectraPhysics) centered at $780 \mathrm{~nm}$ routed into the scanhead and through the sample objective. Fluorescence emission collected from the sample was detected in a nondescanned configuration using cooled photomultiplier tube (PMT) (Hamamatsu). Fluorescence emission in the spectral region of 500-650 nm was collected for detection of broadband autofluorescence from the lung. Second harmonic generation was collected using $800 \mathrm{~nm}$ excitation and a $400 \pm 14 \mathrm{~nm}$ bandpass filter in the nondescanned detector path. The lung was placed on an imaging dish having a \#1.5 coverslip and immersed in phosphate buffered saline. Several sites at the apex of the lobe and the broncho-alveolar region were chosen. At each site $z$-stack was obtained from the outer lung surface using a z-interval of 1 and $150 \mu \mathrm{m}$ total depths using a $40 \times, 0.75$ N.A. water immersion objective, which provided a field of view of $320 \times 320 \mu \mathrm{m}$.

\section{Immunoprecipitation of surfactant protein $A$}

Cells isolated from normal mouse lung, AC rat lung, or 21day AC rat lung cultured with mESCs were washed with $10 \mathrm{~mL}$ of PBS in a conical tube and centrifuged at $400 \mathrm{~g}$ for $10 \mathrm{~min}$. The cell pellet was resuspended in $1 \mathrm{~mL}$ of cold RIPA lysis buffer (50 mM Tris $\mathrm{HCl} \mathrm{pH} 8 ; 150 \mathrm{mM} \mathrm{NaCl}$; 1\% NP-40; and $0.5 \%$ sodium deoxycholate) containing $1 \times$ Protease Inhi- bitor Cocktail (Sigma). The lysate was centrifuged at 10,000 $\mathrm{g}$ for $15 \mathrm{~min}$ at $4^{\circ} \mathrm{C}$. The supernatant was collected and the cell lysate was frozen at this point for long-term storage at $-70^{\circ} \mathrm{C}$. Immunoprecipitation of surfactant protein A was performed following the protocol recommended by Abcam [www.abcam.com/ps/pdf/protocols/Immunoprecipitation $\% 20$ protocol\%20(IP).pdf, accessed on November 2, 2009]. In brief, $50 \mu \mathrm{L}$ of prepared Protein A (Millipore) slurry was added to $500 \mu \mathrm{L}$ of cell lysate and was incubated on ice for 30-60 min to preclear the lysate. The sample was centrifuged at $10,000 \mathrm{~g}$ for $10 \mathrm{~min}$ at $4{ }^{\circ} \mathrm{C}$ and supernatant transferred to a fresh eppendorf. Ten micrograms of antibody to surfactant protein A (Chemicon/Millipore) was added and the sample was incubated at $4{ }^{\circ} \mathrm{C}$ for $1 \mathrm{~h}$. Finally, $50 \mu \mathrm{L}$ of Protein A (Amersham/Pharmacia Biotech) slurry was added and the sample was incubated for $1 \mathrm{~h}$ at $4{ }^{\circ} \mathrm{C}$ on a rocking platform. The beads were collected and washed three times with $500 \mu \mathrm{L}$ of lysis buffer. After the last wash, $50 \mu \mathrm{L}$ of $1 \times$ Laemmli sample buffer was added to the bead pellet. The sample was vortexed and then heated to $90^{\circ} \mathrm{C}-100^{\circ} \mathrm{C}$ for $10 \mathrm{~min}$. The sample was centrifuged at $10,000 \mathrm{~g}$ for $5 \mathrm{~min}$, and supernatant was collected and loaded onto an SDS polyacrylamide gel electrophoresis gel. The gel was finally stained with comassi blue for visual analysis of the immunoprecipitated surfactant A protein.

\section{Statistical analysis}

Statistical analysis was performed using GraphPad InSTAT software (version 2003). Mean values and standard deviation are reported. Analysis of variance was performed and data were subjected to Tukey Kramer multiple comparison test. Mean differences in the values were considered significant when $p$ was less than 0.05 .

\section{Results \\ Decellularization of lung tissue}

Tissues that were not frozen before detergent treatment or that were treated after freezing with polyethylene glycol or Triton X-100 retained the presence of nuclei and DNA after 4 weeks or showed signs of significant degradation of the lung ECM after detergent treatment (data not shown). Higher concentrations of SDS $>2 \%$ resulted in significant loss of the natural ECM and influenced our final selection of 1\% SDS for the detergent treatments. Whole rat lungs (Fig. 2A) were placed in a rotating bioreactor with continually circulated fresh $1 \%$ SDS in the chamber (Fig. $2 \mathrm{~B}, \mathrm{C}$ ). To reach regions deep within the organ we injected 1\% SDS through the trachea three times a day to fully flush the tissues and increase removal of cell debris. Examination of the tissues after 1 week showed the presence of high levels of rat MHC-1 staining (Fig. 2D). DAPI staining of the tissues at this stage

FIG. 3. Examination of gross structure of AC lung matrix. (A) Image of intact AC rat lung showing underlying substructure formed by remnants of bronchi and branching airway ECM. (B, C) Confocal images of $7 \mu$ m frozen sections of AC lung stained for presence of (B) collagen I (green) or (C) elastin (green). Magnification $630 \times$; scale bar in each is $10 \mu \mathrm{m}$. (D) Two photon images of AC rat lung viewed to a depth of $180 \mu \mathrm{m}$ (field of view is $320 \mu \mathrm{m}$ ). SHG microscopy was used to observe fibrillar collagen (red) in this 3D reconstruction, autofluorescence of cells, elastin, and other ECM (green). (E) XY single-plane two-photon imaging of AC rat lung autofluorescence was done at depths of 27, 38, 51, 86, 120, and 179 $\mu \mathrm{m}$ (top and bottom set of three images). In the middle three images, SHG microscopy was used to observe fibrillar collagen (red) at depths of 27, 38 , and $51 \mu \mathrm{m}$. 3D, three-dimensional. Color images available online at www.liebertonline.com/ten. 
FIG. 4. Four micron sections of (A) AC rat lung, (C) Matrigel, (E) Gelfoam, or (G) collagen I/PF-127 hydrogel matrix were photographed using transmitted white light on a Zeiss LSM 510 Meta inverted microscope to show the substructure of each matrix material. (A-H) Scale bar $=20$ $\mu \mathrm{m}$. mESC repopulation of $\mathrm{AC}$ rat lung was compared to repopulation of Matrigel, Gelfoam, and collagen I/PF-127 hydrogel matrices. After seeding with mESCs each $0.5 \mathrm{~cm}^{3}$ piece of matrix material was cultured for 7 days $(\mathbf{B}, \mathbf{D}, \mathbf{F}, \mathbf{H})$. Seven micron frozen sections of each matrix were stained with DAPI to allow for the observation of cell nuclei. Visual inspection using confocal microscopy indicated that more cells were found in (B) AC lung than in (D) Matrigel, (F) Gelfoam, or $(\mathbf{H})$ collagen I/ PF-127 hydrogel matrix. Magnification for $(\mathbf{E}-\mathbf{H})$ was $400 \times$. (I) After 7 days of culture, cells were isolated from each matrix and the number of viable cells was determined using a live/ dead cell viability assay (Molecular Probes, Eugene, OR) with analysis by flow cytometry. Significantly more viable cells were recovered from the AC lung matrix than the other matrices examined $(p<0.001)$. Cells isolated from each matrix were also examined for level of (J) apoptosis (terminal deoxynucleotidyl transferase dUTP nick end labeling [TUNEL] evaluation) using flow cytometry. Significantly more cells from plate compared to 3Dmatrix culture were TUNEL positive $(p<0.001)$. AC lung

also had less TUNEL-positive $(p<0.05)$ cells than Matrigel and collagen I/PF-127 but not when compared to Gelfoam. (K-M) Flow cytometric examination: the cells isolated from each matrix were stained for the presence of (K) cytokeratin, (L) CD31, and $(\mathbf{M})$ pro-SPC to examine the influence of cell matrix on mESC differentiation. (K) Significantly more cells from AC lung matrices were positive for cytokeratin $(p<0.001)$ than for Matrigel or Gelfoam $(p<0.01$ for AC lung compared to collagen I/ PF127), (L) CD31 ( $p<0.001$ for AC lung compared to all matrices used), and (M) pro-SPC ( $p<0.001$ for AC lung compared to all matrices used). ${ }^{*} p<0.001$ for AC lung matrix compared to the all other matrices used and ${ }^{\infty} p<0.05$. mESCs, murine embryonic stem cells; PC, plate culture; AC, acellular; MG, Matrigel; GEF, Gelfoam; C-1, collagen I/PF-127; GF, growth factors; PF-127, pluronic F-127; pro-SPC, pro-surfactant protein C.

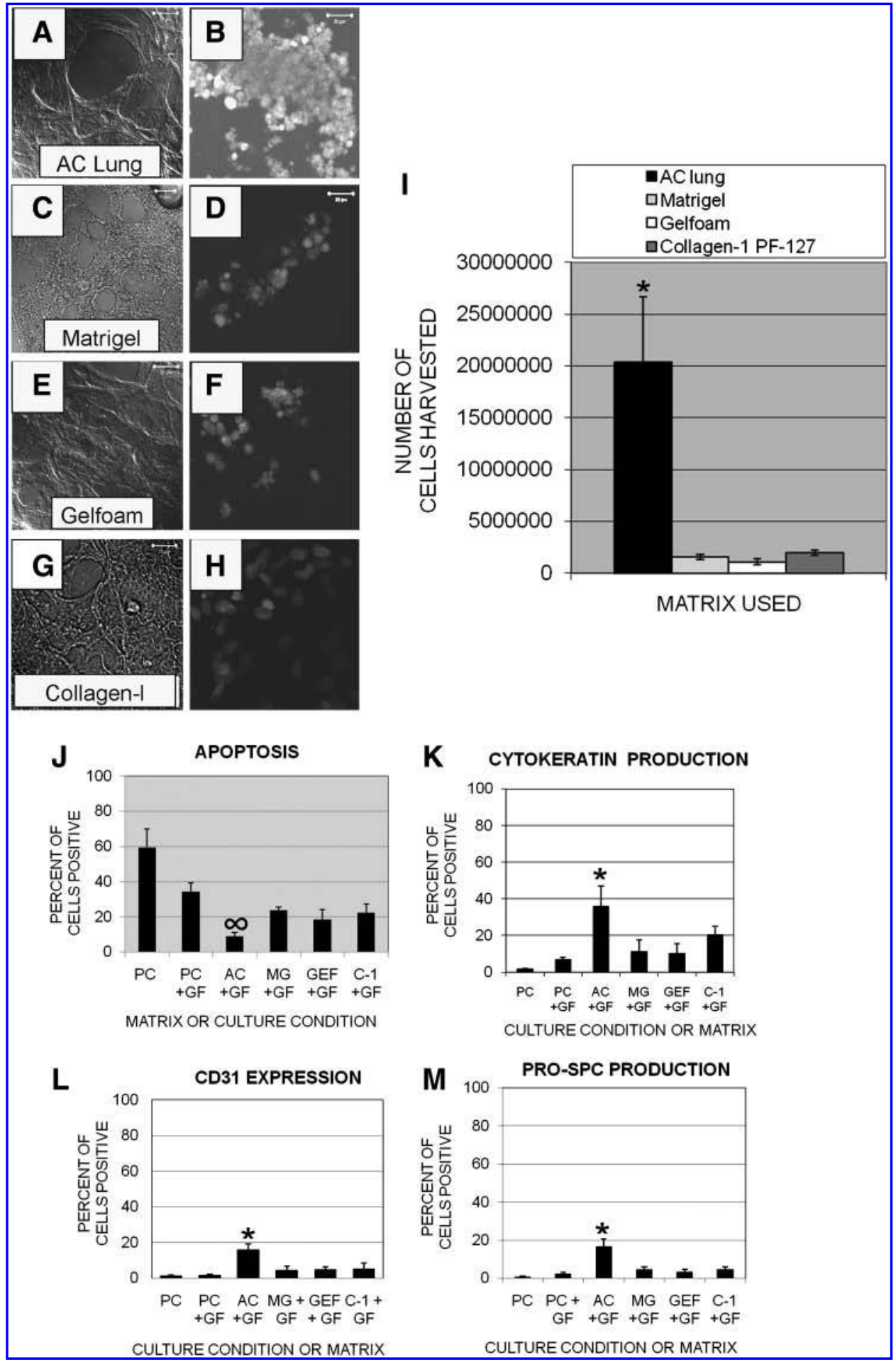


also showed that many intact nuclei were still present (Fig. 2D). After 5 weeks of SDS treatment there was no longer significant Rat MHC-1 staining (Fig. 2E), but DAPI or PI staining indicated that all of the nuclear material was not removed by the detergent treatments alone (Fig. 2E, F). Because of this, tissues were treated with DNAase and RNAase for $24 \mathrm{~h}$, which resulted in production of AC trachea and lung tissue that contained significantly less DNA as estimated by PI staining of tissue sections (Fig. 2G). Confocal analysis suggested that most DNA had been removed at this stage, and examination of the AC lung matrix by electrophoresis on 3\% LMP agarose gels with ethidium bromide confirmed that only trace amounts of DNA remained in the AC rat lung (Fig. $2 \mathrm{H})$ after decellularization using our protocol. The final AC lung tissue had a white glassy appearance (Fig. 2I). There was no positive staining for MHC-1 in the distal airway (Fig. 2J), middle airway (Fig. 2K), bronchus, and trachea (Fig. 2L).

Before tissue culture AC rat lungs with attached trachea were washed in a combination of antibiotics and antimycotic for $24 \mathrm{~h}$, followed with a $24 \mathrm{~h}$ wash in PBS and then a $24 \mathrm{~h}$ wash in DMEM. After decellularization whole lungs still retained obvious signs of the trachea and branching bronchial ECM network within the tissues (Fig. 3A).

Collagen I and elastin are the main components of the pulmonary interstitium and form the basis for the mechanical scaffold or matrix that maintains the integrity of the lung during the process of ventilation. Basement membrane also contains laminin and collagen IV. To determine the influence of the decellularization on the AC lung ECM, $7 \mu \mathrm{m}$ frozen sections of AC lung were stained for expression of collagen I, collagen IV, elastin, and laminin. Collagen I (Fig. 3B, green) and elastin (Fig. 3C, green) were found throughout the $A C$ rat lung matrix although collagen IV (Fig. 3B, red) and laminin (Fig. 3C, red) as well as fibronectin (data not shown) were lost in the decellularization process. Two-photon microscopy was used to produce a 3D reconstruction of AC rat lung viewed from a $0^{\circ}$ angle to a depth of $320 \mu \mathrm{m}$. Autofluorescence (green) was combined with second harmonic generation (SHG-red) to show the relative makeup of the AC lung. SHG microscopy was used to observe fibrillar collagen (red) in this 3D reconstructed z-projection (collapsed z-stack) and cells and other ECM appear green (Fig. 3D). Two-photon microscopy at depths of $27,38,51,86,120$, and $179 \mu \mathrm{m}$ in the AC lung demonstrated that the basic lung architecture was preserved as was the presence of type I fibrillar collagen and that there were no intact cells present within the fully decellularized tissue (Fig. 3E).

\section{Comparison of mESC growth on selected matrices}

Sections of AC lung (Fig. 4A), Matrigel (Fig. 4C), Gelfoam (Fig. 4E), or the type I collagen I/PF-127 hydrogel matrix (Fig. 4G) were examined using transmitted white light to show the substructure of each matrix material. This was done to allow us to evaluate the fibrillar nature and structural composition of each matrix. The influence of composition and rigidity of matrices has been shown to be important for support of a number of biological processes $^{20-26}$ and to significantly influence cell differentiation and tissue development. ${ }^{27-37}$ We then cultured mESC on $\mathrm{AC}$ rat lung matrix (Fig. 4B) and compared cell attachment and survival of cells to mESC cultured on Matrigel (Fig.
4D), Gelfoam (Fig. 4F), or collagen I/PF-127 hydrogel matrix (Fig. $4 \mathrm{H}$ ). For measurements of $\mathrm{DAPI}^{+}$-stained tissue sections, at least three replicate measurements of $\mathrm{DAPI}^{+}$ cells were performed by the same observer in 10 randomly selected slides, which was followed by examination by a second observer. For these studies the intraobserver coefficient of variation was $6 \%$, and the interobserver correlation coefficient was $0.8 \%$ for examination of these slides. Examination of DAPI-stained slides showed that mESCs readily populated the AC lung matrix (Fig. 4B) and cells were found to be evenly spread throughout each $0.5 \mathrm{~cm}^{3}$ portion of this matrix. mESCs did not populate the other matrices evenly and fewer cells were retained by some materials although the same number of cells was used to seed each matrix $\left(2 \times 10^{6}\right.$ mESCs $)$. Flow cytometry results confirmed evaluations of slides, which indicated that fewer cells were retained by the Matrigel (Fig. 4D, I), Gelfoam (Fig. 4F, I), or the collagen I/PF-127 matrix (Fig. 4H, I) compared to viable cell retention by AC lung (Fig. 4B, I) $(p<0.001)$. Cells cultured in 2D tissue culture plates with the culture medium or the lung differentiation medium had significantly higher levels of TUNEL-positive (apoptotic) cells than cells cultured on any of the 3D matrices used (Fig. 4I, J) $(p<0.001)$. AC lung also had significantly fewer TUNEL-positive $(p<0.05)$ cells compared to Matrigel and collagen I/PF-127, but not when compared to Gelfoam (Fig. 4J).

Evaluation of mESCs cultured on AC lung showed significantly higher levels of cells differentiating toward the selected lung lineages, which included expression of cytokeratin-18 (Fig. 4K) $(p<0.001)$ by epithelial cells, CD31 (Fig. $4 \mathrm{~L})(p<0.001)$ by endothelial cells, and pro-SPC (Fig. $4 \mathrm{M})(p<0.001)$ by type II pneumocytes.

\section{Examination of whole lung repopulated with mESCs}

AC lungs (Fig. 5A, left) were seeded with mESCs and cultured for 14 days (Fig. 5) or 21 days (Fig. 6). Recellularization of whole trachea and lungs always resulted in considerable shrinkage of the AC tissues, and the white glassy appearance of the AC material was replaced with a soft fleshy overgrowth of cells (Fig. 5A, right). Two-photon examination of normal freshly isolated rat lung allowed us to observe the pattern of normal cell attachment and organization as well as determine the presence of type I fibrillar collagen (green; Fig. 5B). After decellularization we found that the collagen did not maintain its wavy appearance (Fig. $5 \mathrm{C}, \mathrm{D})$ and this was also true at least initially in the recellularized lung (Fig. 5E). Elastin was found throughout the AC lung before as well as after decellularization (Fig. 5E).

Immunostaining of mESCs grown on AC lung for 14 days showed production of laminin (Fig. 5G) and collagen IV (Fig. 5I) by the differentiating mESCs. Both these components of normal basement membrane were lost during the decellularization process (Fig. 3B, C). This was an important result since laminin connects integrins on the basal surface of epithelial cells to the type IV collagen network of the lamina densa of the basement membrane and forms the framework necessary to support development of lung tissue and proper alveoli formation. Figure 5I also shows the close association of cytokeratin-18-positive epithelial cells with the newly produced collagen IV. Pockets of CD140a platelet-derived 
growth factor receptor- $\alpha$ (PDGFR- $\alpha$ )-positive cells were also seen in whole AC lungs after 2 weeks of culture (Fig. $5 \mathrm{~K}$ ). PDGFR- $\alpha$ plays a major role in lung development and is expressed in the mesenchyme of multiple organs during embryonic development. It is also involved in cell prolifer- ation and differentiation of many tissues, including the lung. ${ }^{38,39}$ There were also small pockets of pro-SPC-positive cells in the distal portions of the AC lung matrix (Fig. 5M) but little indication of complex tissue formation by distal lung cells in tissues isolated after 14 days of culture.

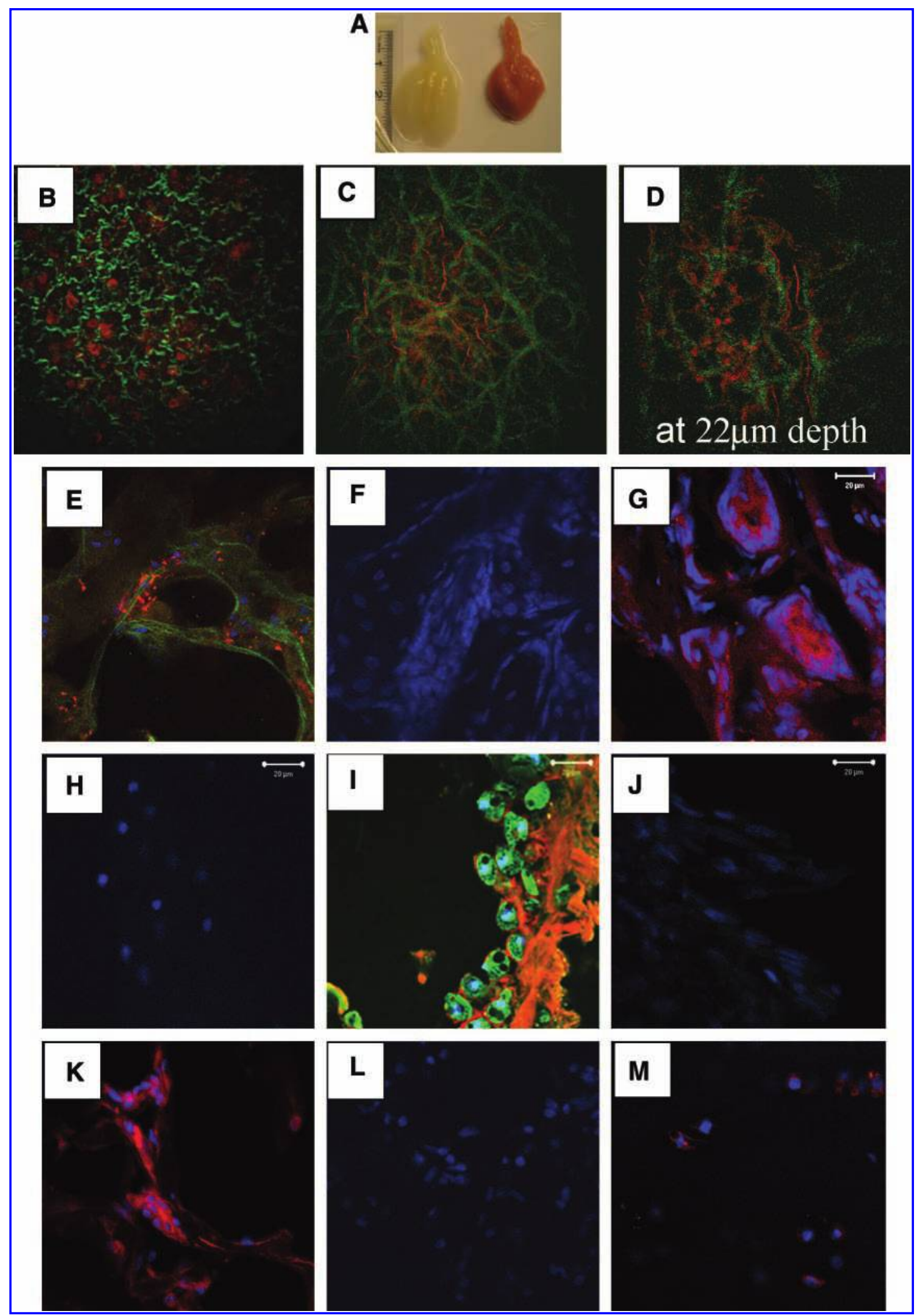




\section{Complex tissue formation}

Complex tissue formation is guided by the interplay between stem cells, the ECM, and the cell environment, all of which contribute to the development of complex tissue and eventually to formation of a functional organ. ${ }^{12,13,22}$ There were indications of complex tissue formation in the upper lung of 14-day cultures where laminin (Fig. 5G) or collagen IV (Fig. 5I) were found, but only small pockets of differentiated cells were found in regions corresponding to the distal lung.

Lungs cultured for 21 days had a uniform fleshy appearance by sight and by touch that was similar to normal lung (Fig. 6A). There was no occlusion of the openings of the trachea or bronchi in the recellularized lungs and sheets of cells (Fig. 6B) that were cytokeratin positive and lined the upper trachea (Fig. 6D). In the lower trachea and carina there were patches of CC10-expressing pan-cytokeratin-positive cells (Fig. 6F). There were also some regions near the main bronchi where strips of $\alpha$-actin-positive smooth muscle cells were seen (Fig. $6 \mathrm{H}$ ). In regions of the upper trachea we also saw groups of cytokeratin-18-positive ciliated epithelial cells (Fig. 6J, K) and pockets of cells expressing CD31, an endothelial cell marker (Fig. 6O).

The cellular composition of the engineered lung changed significantly as one moved from upper trachea and bronchi to more distal lung. In the distal lung there were regions of tissues similar to what would be seen in transitional airways of normal lung in that we saw pro-SPC-positive type II pneumocytes in hollow epithelial cyst-like structures (Fig. 6Q) similar to what has been described in 3D culture of mature type II pneumocytes. ${ }^{40}$ There were also areas of CD31-positive cells in proximity to large formations of pancytokeratin-positive cells in the distal lung (Fig. 6M). These formations (Fig. 6M) were reminiscent of what is seen in vivo during development of vascular tissue in the lung. ${ }^{41}$ In what looked like developing transitional airways or bronchio-alveolar junctions, CC10-expressing cells were found next to developing epithelium (Fig. 6L), which were identified by expression of TTF-1, a transcription factor found in early stages of lung epithelial development. ${ }^{42,43}$

Finally, production of measurable levels of surfactant protein A by whole lung mESC / AC-lung constructs cultured for 21 days demonstrated the capability of AC lung to support maturation of fully functional lung cell types, which includes the production and secretion of surfactant protein $\mathrm{A}$ by Clara cells or type II pneumocytes (Fig. 6R).

\section{Discussion}

The decellularization procedures used in this study were based on those developed previously by Badylak et al. ${ }^{11-14,44}$ to prepare AC organ matrices for organs other than the lung. We did make some alterations to these protocols, including the use of low concentrations of SDS to reduce the loss of distal lung ECM. After multiple decellularization attempts, we found that a combination of mechanical, enzymatic, and physical processes provided the most efficient and gentle way to remove the cells from the underlying lung ECM without significant loss of collagen or elastin, the major structural components of natural lung. Using confocal and two-photon microscopy to examine sequential sections through AC rat lung, we were able to confirm that the decellularization process removed cells, cell membranes, and the majority of nuclear material. Use of confocal microscopy to identify the presence of DNA in PI- or DAPI-stained tissues, while not as sensitive a method as gel electrophoresis, did allow for quick routine estimations to monitor changes in DNA in AC lung, which allowed for development of better procedures to facilitate DNA removal in our studies. Although trace amounts of DNA were found in the AC lung ECM after the decellularization process, the same is true for many commercially available ECM products. ${ }^{12,19}$ Despite the presence of trace amounts of DNA, the clinical efficacy and use of these products has been positive. ${ }^{12,19}$

Multiphoton microscopy of unstained intact sections of the lung provide for evaluation of lung structure and when combined with measurements of second harmonic generation allow for determination of fibrillar collagen I in lung tissues. ${ }^{45,46}$ Two-photon microscopy evaluations of AC rat lung indicated that there did not seem to be a change in pore size or porosity within the decellularized lung tissue and that AC matrix no longer contained the wavy form of collagen I seen in natural lung. As expected, the decellularization process allowed for retention of the basic lung architecture but unfortunately resulted in the loss of collagen IV, laminin, and fibronectin, all of which are important components of the basement membrane of natural lung ECM.

ECM is secreted and constantly modified by cells as they grow and develop. Changes in ECM structure and composition help to influence cell adhesion and provide critical physical cues that orchestrate tissue formation and function. ${ }^{27,28,30,47,48}$ The composition and physical cues provided by ECM are important for growth of all cell types but are critical for differentiation of ESCs. ${ }^{49-51}$ Composition, concentration, and strength of matrix materials such as collagen,

FIG. 5. (A) Gross image of AC rat lung (left) next to mESC-recellularized lung (right) after culture for 14 days showing contraction of the ECM. (B-D) Two-photon imaging: 3D reconstructions of (B) normal fresh rat lung tissue, (C) AC lung, and (D) recellularized rat lung tissue. Green color corresponds to SHG showing collagen and red to autofluorescence of cells, elastin, and other ECM. (D) Recellularized lung tissue imaged at a depth of $22 \mu \mathrm{m}$. (E) Confocal image of $7 \mu \mathrm{m}$ frozen section of AC lung recellularized with mESC after 14 days of culture stained for expression of collagen I (green) and elastin (red). Magnification $630 \times$. (F) Control for G stained with secondary antibody donkey anti-goat IgG conjugated to Alexa Fluor 680 and (G) sections stained for laminin, scale bar $=20 \mu \mathrm{m}$. (H) Control for (I) (scale bar $=20 \mu \mathrm{m}$ ) stained with secondary antibody rabbit anti-mouse IgG conjugated to Alexa Fuor 488 followed by donkey anti-goat conjugated to Alexa Fluor 680 and (I) sections stained for cytokeratin-18 (green) and collagen IV (red), scale bar $=20 \mu \mathrm{m}$. Magnification for (E-I) was 630 $\times$. (J) Control for $(\mathbf{K})($ scale bar $=20 \mu \mathrm{m})$ stained with IgG isotype antibody conjugated to Pe-CY5 and evaluation of (K) CD140a (PDGFR- $\alpha$ ) expression (red). (L) Control for (M) stained with rabbit anti-mouse IgG conjugated to Alexa Fluor 488 and (M) evaluation of expression of pro-SPC (red) by type II pneumocytes. Magnification for (E-M) was $400 \times$. (E-M) Tissues were counterstained with DAPI to view nuclei (blue). PDGFR- $\alpha$, platelet-derived growth factor receptor- $\alpha$. Color images available online at www.liebertonline.com/ten. 


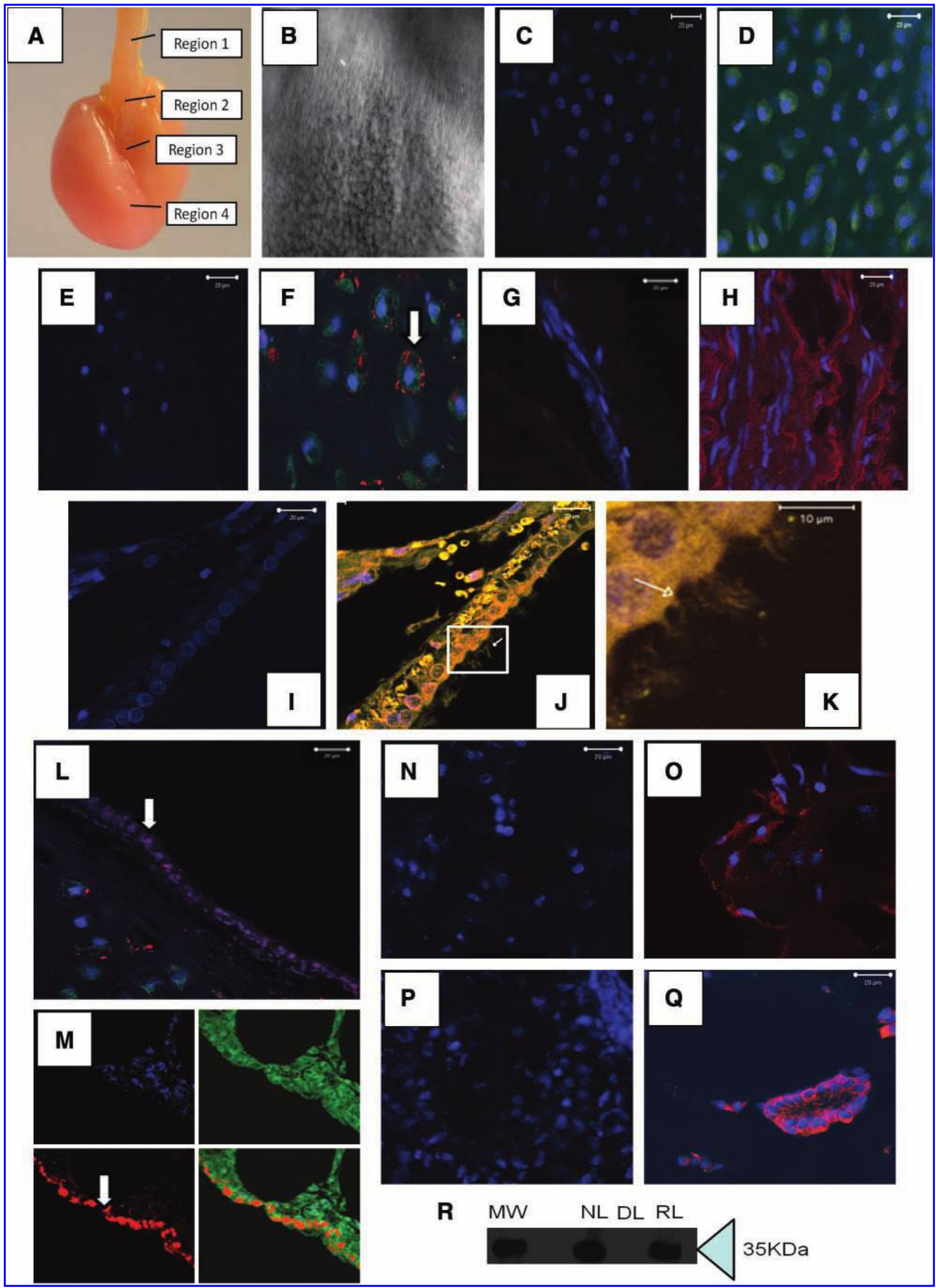


fibronectin, and laminin have been shown to strongly influence ESC differentiation. ${ }^{52}$ Because of this we used mESC culture to examine the capability of AC rat lung to support cell survival, attachment, differentiation, and complex tissue formation. Embryonic stem cells generally have low rates of differentiation to lung lineages ${ }^{5,54}$ although one study reported that $24 \%$ of mESCs had been differentiated to surfactant protein $\mathrm{C}$ producing cells in aggregate cocultures of mESCs and fetal lung cells. ${ }^{55,56}$ We were hoping that AC lung would retain enough of the natural ECM to be able to influence the efficiency of mESC lung cell lineage differentiation and support the production of the variety of cell types necessary to produce lung tissue. We also hoped that whole lung cultures that possess very different $3 \mathrm{D}$ region-specific ECM compositions, stiffness, and porosities would promote region-specific differentiation based on site-specific cues.

To support the recellularization process we created a lung environment by culturing $\mathrm{mESC} /$ matrix constructs with a combination of previously identified soluble lung-specific growth factors ${ }^{3,57}$ supplemented with mature lung homogenate. ${ }^{58,59}$ We used a rotary bioreactor because it has been shown to create a supportive fluid environment for engineered tissue constructs similar to what one would see in vivo for fetal development during organogenesis. ${ }^{60}$ Rotary bioreactor culture also reduces sheer stress and maintains a constant flow of nutrients to the developing tissue.

Normal cells probe, pull, and push at their surrounding matrix and the forces generated by these interactions of cells with ECM influence both the response of individual cells and the subsequent development of tissues. Gelfoam is a gelatinbased sponge, made predominantly of denatured type I collagen, and is the simplest of the matrices we examined. The collagen I PF-127 hydrogel matrix used in this study is also simple matrix and only has one component of normal lung ECM, collagen I, immersed within the PF-127 soft hydrogel. Matrigel contains the basement membrane com- ponents collagen IV and laminin and small amounts of other ECM materials, making it more complex than the previously mentioned matrix materials. AC rat lung contains collagen I, elastin, and small amounts of other ECM. We felt that Matrigel and AC lung, due to fibrosity alone, were fairly close in terms of matrix stiffness. In our assessment of $4 \mu \mathrm{m}$ sections of each of these matrices (seen in Fig. 4A, C, E, G) we categorized them according to degree of porosity content where Gelfoam $<$ Collagen I/PF-127 < Matrigel $<$ AC lung. In terms of fibrosity or stiffness as estimated by fiber content and ECM components we categorized them according to degree of stiffness where Gelfoam $<$ Collagen I/PF-127 $<$ Matrigel $\leq \mathrm{AC}$ lung. Even within the lung there are regional differences in ECM composition, fibrosity, and porosity. In our experiments we found that when comparing the fibrosity and porosity of regions within whole lung it was obvious that upper lung and trachea were much more fibrous and had less porosity than distal lung (Fig. 2J-L). Upper lung had increased stiffness (fibrosity) compared to distal lung and supported the differentiation of mESC toward lineages of cells that are normally found in upper lung and trachea such as Clara cells and cytokeratin-positive epithelial cells. In our studies Clara cells and ciliated epithelial cells were only seen in upper lung, and pro-SPC-positive cells were only seen in regions of distal lung.

After 7 days we assessed the phenotype of mESC grown in plate culture, on AC rat lung or on Gelfoam, Matrigel, and collagen I/PF-127 matrices. We examined apoptosis induction since programmed cell death or apoptosis is known to play an important role in embryo development, contributing to the appropriate formation of various organs and structures. We anticipated finding comparable levels of apoptosis in all of the cell/matrix constructs after 1 week of culture regardless of the matrix used to form cell constructs. We found that plate or 2D culture always had the highest levels of apoptosis and was the least efficient system to induce

FIG. 6. (A) Gross image of recellularized rat lung after 21 days of culture. Region 1 includes the trachea, region 2 corresponds to the carina and upper bronchi, region 3 includes both bronchi and bronchioles, and region 4 is distal lung. The following micrographs correspond to the general regions outlined in this figure (1-4). (B) Phase-contrast image of differentiated mESC in the trachea (in region 1) showing sheets of cells lining the trachea. Magnification $100 \times$. Confocal images of $7 \mu \mathrm{m}$ frozen sections of regions 1 and 2 of recellularized lung matrix after 21 days of bioreactor culture demonstrating mESC differentiation. (C) Control for (D) (scale bar $=20 \mu \mathrm{m})$ stained with secondary antibody rabbit anti-mouse IgG conjugated to Alexa Fluor 488 and (D) cytokeratin-18 in cells lining the trachea (scale bar $=20 \mu \mathrm{m}$ ). (E) Control for $(\mathbf{F})$ (scale bar $=20 \mu \mathrm{m})$ stained with secondary antibody rabbit anti-mouse IgG conjugated to Alexa Fluor 488 followed by donkey anti-goat IgG conjugated to Alexa Fluor 680 and (F) expression of cytokeratin-18 (green) and CC10 (red) (scale bar $=20 \mu \mathrm{m}$ ). Arrow points to Clara cells with characteristic intracellular granular staining for CC10. Magnification $630 \times($ scale bar $=20 \mu \mathrm{m})$. Confocal images of predominant cell type found in region 2 are shown in $(\mathbf{G}-\mathbf{K})$. (G) Control for $(\mathbf{H})$ stained with secondary goat anti-rat-antibody conjugated to Alexa Fluor 680 and $(\mathbf{H})$ expression of $\alpha$-actin (red) found in small pockets near bronchi. Magnification $400 \times(\mathrm{scale} b a r=20 \mu \mathrm{m}) .(\mathbf{I})$ Control for $(\mathrm{J}-\mathrm{L})($ scale bar $=20 \mu \mathrm{m})$ stained with rabbit anti-mouse IgG conjugated to Alexa Fluor 488 secondary antibody (green), goat anti-rabbit highly cross absorbed antibody conjugated to Alexa Fluor 555 (purple), and donkey anti-goat conjugated to Alexa Fluor 680 (red) and (J) expression of cytokeratin-18 (green) by small isolated regions of ciliated tracheal epithelial cells lining area just above the carina (scale bar $=20 \mu \mathrm{m}$ ). Magnification $400 \times$. (K) Enlargement of area in white box to show $(\mathrm{J})$ a small region of ciliated epithelia cells (arrow) (scale bar $=20 \mu \mathrm{m}$ ). ( $\mathbf{L}, \mathbf{M})$ Confocal evaluation of sections from region 3 (scale bar $=20 \mu \mathrm{m}$ ). (L) Formation of stratified tissue showing production of thyroid transcription factor-1 (purple) in cells lining the bronchial lumen (arrow) along side of cells expressing CC10 (red) and cytokeratin-18 (green) (scale bar $=20 \mu \mathrm{m}$ ). Magnification $400 \times$. (M) Pan-cytokeratin (green) and CD31 (red) expression by cells found in region 3. Arrow points to line of CD31-positive endothelial cells that developed along side of the cytokeratin-positive cells. Magnification $200 \times$. (N-Q) Confocal evaluation of sections from region 4. (N) Isotype control for IgG allophycocyanin and (O) expression of CD31 (red) by developing endothelial cells. Magnification $630 \times$. (P) Control stained with Rhodamine red X donkey anti-rabbit IgG and (Q) expression of pro-SPC (red)-positive cells in cyst-like structures (scale bar $=20 \mu \mathrm{m}$ ). Magnification $630 \times$. (R) Immunoprecipation of surfactant protein A by cells isolated from normal lung, AC rat lung, or a 21-day culture of mESC recellularized lung. (D-R) Tissues were counterstained with DAPI to view nuclei (blue). CC10, Clara cell protein 10; MW, molecular weight; NL, normal lung; DL, decellularized lung; RL, recellularized lung. Color images available online at www.liebertonline.com/ten. 
production of differentiation-associated proteins specific to epidermal or endodermal lineages compared to any of the 3D matrix cultures, although the same numbers of cells and differentiation medium was used. We determined that AC lung constructs retained cells better, enhanced cell survival, and induced higher levels of lung-specific lineages than did collagen I/PF127, Matrigel, or Gelfoam matrices. An explanation for this observation might be that even with the ECM changes seen as a result of the decellularization protocol, simple matrices such as Matrigel, Gelfoam, or collagen I/PF127 do not provide the requisite physical cues or mechanical influences necessary to support good lung-site-specific differentiation of cells. This is consistent with the studies that support the premise that local growth rate of tissue formed by cells is influenced by the geometry as well as the consistency and structure of the ECM. ${ }^{27-31,45,61-63}$

To determine if AC lung matrix could influence mESC 3D tissue development, we examined tissue development in whole AC rat lung constructs cultured in a rotary bioreactor for 14 days or 21 days. Our results showed that by 14 days of culture, cellular structures formed by the differentiating mESC had secreted ECM components lacking in AC lung, including both collagen IV and laminin as demonstrated by immunostaining. We also saw areas where groups of cells expressed CD140a or PDGFR- $\alpha$. This was an important result because PDGFR- $\alpha$ has been shown to be crucial for alveolar myofibroblast ontogeny and alveogenesis. ${ }^{38,39}$ Expression of PDGFR- $\alpha$ in our cultures was a good indication that mESC differentiation toward lung lineages and formation of nascent ECM by developing myofibroblasts was in process.

Type II alveolar epithelial cells (TYII AECs) are the first type of AEC to form in human and rodents during normal fetal lung development. Although we saw differentiation of cells to endodermal lineages by day 14 , we did not see extensive 3D complex tissue formation or extensive production of TYII AECs. By 21 days we had hoped to see complex tissue formation in whole lung cultures since the normal gestation period for C57BL6 mice is 19-22 days. In 21-day lung cultures site-specific differentiation of mESCs was evidenced by production of discrete regions of $\alpha$-actinexpressing smooth muscle cells, cytokeratin-18, and CC10expressing cells in regions that included both the trachea and bronchi (regions 1 and 2 of Fig. 6A). Along the inner surfaces of the trachea and bronchi, we were able to detect sheets of cells that expressed epithelial cell markers such as TTF-1, cytokeratin-18, or CC10, which also included a few ciliated cells. An extensive large-scale development of ciliated epithelial cells did not occur because the use of the bioreactor for cell culture did not provide an adequate air interface to the culture, which has been shown to be necessary to induce maturation and development of ciliated epithelia. ${ }^{64}$

In fetal lung development, AEC differentiation begins during the canalicular stage of development; however, true alveoli formation does not occur until much closer to birth. In our 21-day cultures immunohistochemical staining showed formation of sheets of TTF-1-expressing immature epithelial cells and cyst-like formations of pro-SPC-expressing TYII AEC in the distal lung. Other indications of epithelial cell differentiation include the secretion of the major lung surfactant protein, surfactant protein A (SPA). In the mouse, SPA is first detected in amniotic fluid at 17 days postcoitum and amounts of SPA rise progressively to term (19-21 days postcoitum) ${ }^{65}$ Secretion of measurable amounts of surfactant protein A by TYII AEC or Clara cells was seen in 21-day cultures, indicating that maturation of the lung tissues was taking place although not at the same rate as occurs in utero.

A vascular supply is critical to the formation of good functional tissues, and because of this we evaluated whether mESCs were able to differentiate into endothelial lineages and organize into vessels in the engineered tissues. Immunochemical staining for CD31 showed that AC rat lung supported both higher levels of endothelial cell differentiation and, in whole-lung cultures, the formation of very simple capillary-like networks. The site-specific cues provided by AC lung ECM that contributed to the in vitro differentiation of mESC are unknown at this time and are presently being investigated by our laboratory. Further studies comparing the tensile strength of the AC lung (with and without cells) to the normal lung need to be done to further assess the effects of the decellularization process on the remaining collagen and elastin. These data suggest that AC lung retains enough scaffold-mediated biological signals to direct mESC toward lung-specific lineages and to guide lung-specific tissue development in vitro. These data also demonstrate the ability of ECM cues to influence mESC differentiation in a site-specific manner.

In summary, we found that AC natural lung allowed for better retention of cells with more differentiation of mESCs into epithelial and endothelial lineages than was seen in matrices previously used to generate engineered lung. ${ }^{3,4,6-8}$ In constructs formed from mESCs and whole AC lung we saw indications of differentiating ESC organized into 3D structures reminiscent of complex tissues. In whole AC lung/mESC constructs we saw expression of TTF-1, an immature lung epithelial cell marker; pro-SPC, a type II pneumocyte marker; PECAM-1/CD31, an endothelial cell marker; CD140a or PDGFR- $\alpha$, which is expressed in mesenchyme during embryonic development; and CC10, a Clara cell marker, as well as development of a few discrete pockets of ciliated epithelial cells. There was also evidence of site-specific differentiation in the trachea and distal lung. In the trachea we saw formation of sheets of cytokeratin-18-positive cells and CC10-expressing Clara cells, near the carina and upper bronchi. Type II pneumocytes found in the distal lung formed hollow alveolarlike cysts lined by a monolayer of epithelial cells, which produced both pro-SPC, the nonsecreted form of surfactant protein $C$, as well as production of SPA.

\section{Conclusion}

In this article, the process for decellularization of natural lung to produce a functional AC matrix for engineering of lung tissue was presented. We showed that AC rat lung supported better cell adhesion, allowing for more successful population of the matrix, as well as enhanced lung lineage selection by mESCs than did Matrigel, Gelfoam, and collagen I/PF-127 hydrogel matrices. We found that 3D culture of mESCs was always better than plate culture and that 3D culture resulted in better cell survival and higher efficiencies of lung-specific differentiation. Further, we proved that AC lung ECM retains enough of the natural lung collagen and elastin network to appropriately support development of lung-specific cell types in a site-specific manner. The production and use of decellularized lung to support develop- 
ment of lung tissue may lead to design of better synthetic matrices for clinical use and to the eventual production of engineered lung tissues on matrices that are suitable for regenerative medicine purposes.

\section{Acknowledgments}

The authors would like to thank Kenneth Frohne, IT Department of the Galveston National Laboratory, for critical discussions related to graphic design as well as computer and publishing software support.

\section{Disclosure Statement}

No competing financial interests exist.

\section{References}

1. Dunsmore, S.E. Treatment of COPD: a matrix perspective. Int J COPD 3, 113, 2008.

2. Yuan, H., Ingenito, E.P., and Suki, B. Dynamic properties of lung parenchyma: mechanical contributions of fiber network and interstitial cells. J Appl Physiol 83, 1420, 1997.

3. Cortiella, J., Nichols, J.E., Kojima, K., Bonassar, L.J., Dargon, P., Roy, A.K., Vacanti, M.P., Niles, J.A., and Vacanti, C.A. Tissue-engineered lung: an in vivo and in vitro comparison of polyglycolic acid and pluronic F-127 hydrogel/somatic lung progenitor cell constructs to support tissue growth. Tissue Eng 12, 1213, 2006.

4. Mondrinos, M.J., Koutzaki, S., Jiwanmall, E., Li, M., Dechadarevian, J.P., Lelkes, P.I., and Finck, C.M. Engineering threedimensional pulmonary tissue constructs. Tissue Eng 12, 717, 2006.

5. Mondrinos, M.J., Koutzaki, S., Lelkes, P.I., and Finck, C.M. A tissue-engineered model of fetal distal lung tissue. Am J Physiol Lung Cell Mol Physiol 293, L639, 2007.

6. Andrade, C.F., Wong, A.P., Waddell, T.K., Keshavjee, S., and Liu, M. Cell-based tissue engineering for lung regeneration. Am J Physiol Lung Cell Mol Physiol 292, L510, 2007.

7. Chen, P., Marsilio, E., Goldstein, R.H., Yannas, I.V., and Spector, M. Formation of lung alveolar-like structures in collagen-glycosaminoglycan scaffolds in vitro. Tissue Eng 11, 1436, 2005.

8. Sugihara, H., Toda, S., Miyabara, S., Fujiyama, C., and Yonemitsu, N. Reconstruction of alveolus-like structure from alveolar type II epithelial cells in three-dimensional collagen gel matrix culture. Am J Pathol 142, 783, 1993.

9. Nichols, J.E., and Cortiella, J. Engineering of a complex organ: progress toward development of a tissue-engineered lung. Proc Am Thorac Soc 5, 723, 2008.

10. Nichols, J.E., Niles, J.A., and Cortiella, J. Design and development of tissue engineered lung: progress and challenges. Organogenesis 5, 57, 2009.

11. Badylak, SF. The extracellular matrix as a scaffold for tissue reconstruction. Semin Cell Dev Biol 13, 377, 2002.

12. Badylak, S.F., Freytes, D.O., and Gilbert, T.W. Extracellular matrix as a biological scaffold material: structure and function. Acta Biomater 5, 1, 2009.

13. Gilbert, T.W., Sellaro, T.L., and Badylak, S.F. Decellularization of tissues and organs. Biomaterials 27, 3675, 2006.

14. Sellaro, T.L., Ravindra, A.K., Stolz, D.B., and Badylak, S.F. Maintenance of hepatic endothelial cell phenotype in vitro organ-specific extracellular matrix scaffolds. Tissue Eng 13, 2301, 2007.

15. Ott, H.C., Matthiesen, T.S., Goh, S.K., Black, L.D., Kren, S.M., Netoff, T.I., and Taylor, D.A. Perfusion-decellularized matrix: using nature's platform to engineer a bioartificial heart. Nat Med 14, 213, 2008.

16. Macchiarini, P., Jungebluth, P., Go, T., Asnaghi, M.A., Rees, L.E., Cogan, T.A., Dodson, A., Martorell, J., Bellini, S., Parnigotto, P.P., Dickinson, S.C., Hollander, A.P., Mantero, S., Conconi, M.T., and Birchall, M.A. Clinical transplantation of a tissue-engineered airway. Lancet 372, 2023, 2008.

17. Lwebuga-Mukasa, J.S., Ingbar, D.H., and Madri, J.A. Repopulation of human alveolar matrix by adult rat type II pneumocytes in vitro. Exp Cell Res 162, 423, 1986.

18. Gillette, B.M., Jensen, J.A., Tang, B., Yang, G.J., BazarganLari, A., Zhong, M., and Sia, S.K. In situ collagen assembly for integrating microfabricated three-dimensional cellseeded matrices. Nat Mater 7, 636, 2008.

19. Gilbert, T.W., Freund, J.M., and Badylak, S.F. Quantification of DNA in biologic scaffold materials. J Surg Res 152, 135, 2009.

20. Ingber, D.E. Tensegrity I. Cell structure and hierarchical systems biology. I Cell Sci 116, 1157, 2003.

21. Ingber, D.E. Tensegrity II. How structural networks influence cellular information processing networks. J Cell Sci 116, 1397, 2003.

22. Chan, G., and Mooney, D.J. New materials for tissue engineering: towards greater control over the biological response. Trends Biotechnol 26, 382, 2009.

23. Suki, B., and Bates, J.H.T. Extracellular matrix mechanics in lung parenchymal disease. Respir Physiol Neurobiol 163, 33, 2008.

24. Rosso, F., Giordano, A., Barbarisi, M., and Barbarisi, A. From cell-ecm interactions to tissue engineering. J Cell Physiol 199, 174, 2004.

25. Ritter, M.C., Jesudason, R., Majumdar, A., Stamenovic, D., Buczek-Thomas, J.A., Stone, P.J., Nugent, M.A., and Suki, B. A zipper network model of the failure mechanics of extracellular matrices. Proc Natl Acad Sci USA 106, 1081, 2009.

26. Yuan, H., Ingenito, E.P., and Suki, B. Dynamic properties of lung parenchyma: mechanical contributions of fiber network and interstitial cells. J Appl Physiol 83, 1420, 1997.

27. Engler, A.J., Sen, S., Sweeney, H.L., and Discher, D.E. Matrix elasticity directs stem cell lineage specification. Cell 126, 677, 2006.

28. Engler, A.J., Sweeney, H.L., Discher, D.E., and Schwarzbauer, J.E. Extracellular matrix elasticity directs stem cell differentiation. J Musculoskelet Neuronal Interact 7, 335, 2007.

29. Vogel, V., and Sheetz, M. Local force and geometry sensing regulate cell functions. Nat Rev Mol Cell Biol 7, 265, 2006.

30. McBeath, R., Pirone, D.M., Nelson, C.M., Bhadriraju, K., and Chen, C.S. Cell shape, cytoskeletal tension, and RhoA regulate stem cell lineage commitment. Dev Cell 6, 483, 2004.

31. Shannon, J.M., Mason, R.J., and Jennings, S.D. Functional differentiation of alveolar type II epithelial cells in vitro: effects of cell shape, cell-matrix interactions and cell-cell interactions. Biochim Biophys Acta 931, 143, 1987.

32. Baker, S.C., Rohman, G., Southgate, J., and Cameron, N.R. The relationship between the mechanical properties and cell behaviour on PLGA and PCL scaffolds for bladder tissue engineering. Biomaterials 30, 1321, 2009.

33. Lund, A.W., Yener, B., Stegemann, J.P., and Plopper, G.E. The natural and engineered $3 \mathrm{D}$ microenvironment as a regulatory cue during stem cell fate determination. Tissue Eng Part B 15, 371, 2009.

34. Reing, J.E., Zhang, L., Myers-Irvin, J., Cordero, K.E., Freytes, D.O., Heber-Katz, E., Bedelbaeva, K., McIntosh, D., Dewilde, A., Braunhut, S.J., and Badylak, S.F. Degradation products of extracellular matrix affect cell migration and proliferation. Tissue Eng Part A 15, 605, 2009. 
35. Guerra, L., Dellambra, E., Panacchia, L., and Paionni, E. Tissue engineering for damaged surface and lining epithelia: stem cells current clinical applications, and available engineered tissues. Tissue Eng Part B 15, 91, 2009.

36. Kim, K.K., Kugler, M.C., Wolters, P.J., Robillard, L., Galvez, M.G., Brumwell, A.N., Sheppard, D., and Chapman, H.A. Alveolar epithelial cell mesenchymal transition develops in vivo during pulmonary fibrosis and is regulated by the extracellular matrix. Proc Natl Acad Sci USA 103, 13180, 2006.

37. Ranels, D.E., and Rannels, S.R. Influence of the extracellular matrix on type 2 cell differentiation. Chest 96, 165, 1989.

38. Zhang, X.Q., Afink, G.B., Hu, X.R., Forsberg-Nilsson, K., and Nister, M. Gli1 is not required for Pdgfr $\alpha$ expression during mouse embryonic development. Differentiation 73, 109, 2005.

39. Bostrom, H., Willetts, K., Pekny, M., Leveen, P., Lindahl, P., Hedstrand, H., Pekna, M., Hellstrom, M., Gebre-Medhin, S., Schalling, M., Nilsson, M., and Kurland, S. PDGF-A signaling is a critical event in lung alveolar myofibroblast development and alveogenesis. Cell 85, 863, 1996.

40. Yu, W., Fang, X., Ewald, A., Wong, K., Hunt, C.A., Werb, Z., Matthay, M.A., and Mostov, K. Formation of cysts by alveolar type II cells in three-dimensional culture reveals a novel mechanism for epithelial morphogenesis. Mol Biol Cell 18, 1693, 2007.

41. Hislop, A.A. Airway and blood vessel interaction during lung development. J Anat 201, 325, 2002.

42. Boggaram, V. Thyroid transcription factor-1 (TTG-1/ Nkx2.1/T1TF1) gene regulation in the lung. Clin Sci 116, 27, 2009.

43. Carraro, G., Perin, L., Sedrakyan, S., Giuliani, S., Tiozzo, C., Lee, J., Turcatel, G., De Langhe, S.P., Driscoll, B., Bellusci, S., Minoo, P., Atala, A., De Filippo, R.E., and Warburton, D. Human amniotic fluid stem cells can integrate and differentiate into epithelial lung lineages. Stem Cells 26, 2902, 2008.

44. Brown, B., Lindberg, K., Reing, J., Stolz, D.B., and Badylak, S.F. The basement membrane component of biologic scaffolds derived from extracellular matrix. Tissue Eng 12, 519, 2006.

45. Agarwal, A., Coleno, M.L., Wallace, V.P., Wu, W.Y., Sun, C.H., Tromberg, B.J., and George, S.C. Two-photon laser scanning microscopy of epithelial cell-modulated collagen density in engineered human lung tissue. Tissue Eng 7, 191, 2001.

46. Pena, A.M., Fabre, A., Debarre, D., Marchal-Somme, J., Crestani, B., Martin, J.L., Beaurepaire, E., and Schanne-Klein, M.C. Three-dimensional investigation and scoring of extracellular matrix remodeling during lung fibrosis using multiphoton microscopy. Microsc Res Tech 70, 162, 2007.

47. Nelson, C.M. Geometric control of tissue morphogenesis. Biochim Biophys Acta 1793, 903, 2009.

48. Engler, A.J., Humbert, P.O., Wehrle-Haller, B., and Weaver, V.M. Multiscale modeling of form and function. Science 324, 208, 2009

49. Levenberg, S., Huang, N.F., Lavik, E., Rogers, A.B., Itskovitz-Eldor, J., and Langer R. Differentiation of human embryonic stem cells on three-dimensional polymer scaffolds. Proc Natl Acad Sci USA 100, 12741, 2003.

50. Hwang, N.S., Kim, M.S., Sampattavanich, S., Baek, J.H., Zhang, Z., and Elisseeff, J. Effects of three-dimensional culture and growth factors on the chondrogenic differentiation of murine embryonic stem cells. Stem Cells 24, 284, 2006.

51. Yim, E.K., and Leong, K.W. Proliferation and differentiation of human embryonic germ cell derivatives in bioactive polymeric fibrous scaffold. J Biomater Sci Polym Ed 16, 1193, 2005.

52. Battista, S., Guarnieri, D., Borselli, C., Zeppetelli, S., Borzacchiello, A., Mayol, L., Gerbasio, D., Keene, D.R., Ambrosio, L., and Netti, P.A. The effect of matrix composi- tion of 3D constructs on embryonic stem cell differentiation. Biomaterials 26, 6194, 2005.

53. Rippon, H.J., Lane, S., Qin, M., Ismail, N.S., Wilson, M.R., Takata, M., and Bishop, A.E. Embryonic stem cells as a source of pulmonary epithelium in vitro and in vivo. Proc Am Thorac Soc 5, 717, 2008.

54. Samadikuchaksaraei, A., Cohen, S., Isaac, K., Rippon, H.J., Polak, J.M., Bielby, R.C., and Bishop, A.E. Derivation of distal airway epithelium from human embryonic stem cells. Tissue Eng 12, 867, 2006.

55. Denham, M., Cole, T.J., and Mollard, R. Embryonic stem cells form glandular structures and express surfactant protein $\mathrm{C}$ following culture with dissociated fetal respiratory tissue. Am J Physiol Lung Cell Mol Physiol 290, L1210, 2006.

56. Denham, M., Conley, B.J., Olsson, F., Gulluyan, L., Cole, T.J., and Mollard, R. A murine respiratory-inducing niche displays variable efficiency across human and mouse embryonic stem cell species. Am J Physiol Lung Cell Mol Physiol 292, L1241, 2007.

57. Rippon, H.J., Polak, J.M., Qin, M., and Bishop, A.E. Derivation of distal lung epithelial progenitors from murine embryonic stem cells using a novel three-step differentiation protocol. Stem Cells 24, 1389, 2006.

58. Qin, M., Tai, G., Collas, P., Polak, J.M., and Bishop A.E. Cell extract-derived differentiation of embryonic stem cells. Stem Cells 23, 712, 2005.

59. Van Vranken, B.E., Romanska, H.M., Polak, J.M., Rippon, H.J., Shannon, J.M., and Bishop, A.E. Coculture of embryonic stem cells with pulmonary mesenchyme: a microenvironment that promotes differentiation of pulmonary epithelium. Tissue Eng 11, 1177, 2005.

60. Lappa, M. Organic tissues in rotating bioreactors: fluidmechanical aspects, dynamic growth models and morphological evolution. Biotechnol Bioeng 84, 518, 2003.

61. Voytik-Harbin, S.L. Three-dimesional extracellular matrix substrates for cell culture. Methods Cell Biol 63, 561, 2001.

62. Rumpler, M., Woesz, A., Dunlop, J.W.C., van Dongen, J.T., and Fratzl, P. The effect of geometry on three-dimensional tissue growth. J Royal Soc Interface R Soc 5, 1173, 2008.

63. Nichols, J.E., Cortiella, J., Lee, J., Niles, J.A., Cuddihy, M., Wang, S., Bielitzki, J., Cantu, A., Mlcak, R., Valdivia, E., Yancy, R., McClure, M.L., and Kotov, N.A. In vitro analog of human bone marrow from 3D scaffolds with biomimetic inverted colloidal crystal geometry. Biomaterials 30, 1071, 2009.

64. Gray, T.E., Guzman, K., Davis, C.W., Abdullah, L.H., and Nettesheim, P. Mucociliary differentiation of serially passaged normal human tracheobronchial epithelial cells. Am J Respir Cell Mol Biol 14, 104, 1996.

65. Condon, J.C., Jeyasuria, P., Faust, J.M., and Mendelson, C.R. Surfactant protein secreted by the maturing mouse fetal lung acts as a hormone that signals the initiation of parturition. Proc Natl Acad Sci USA 101, 4978, 2004.

Address correspondence to: Joaquin Cortiella, M.D., M.P.H. University of Texas Medical Branch Department of Anesthesiology

301 University Blvd., Route 0591 Galveston, Texas 77555-0591

E-mail: jocortie@utmb.edu

Received: November 11, 2009 Accepted: March 17, 2010 Online Publication Date: April 19, 2010 
This article has been cited by:

1. Rick A. Wetsel, Dachun Wang, Daniel G. Calame. 2011. Therapeutic Potential of Lung Epithelial Progenitor Cells Derived from Embryonic and Induced Pluripotent Stem Cells. Annual Review of Medicine 62:1, 95-105. [CrossRef] 